\title{
CORRECTION
}

\section{Correction to: Palliative care interventions in intensive care unit patients}

Victoria Metaxa ${ }^{1 *} \mathbb{D}$, Despina Anagnostou², Savvas Vlachos ${ }^{1}$, Nishkantha Arulkumaran ${ }^{3}$, Sherihane Bensemmane ${ }^{4}$, Ingeborg van Dusseldorp ${ }^{5}$, Rebecca A. Aslakson ${ }^{6,7}$, Judy E. Davidson ${ }^{8}$, RikT. Gerritsen ${ }^{9}$, Christiane Hartog ${ }^{10,11}$ and J. Randall Curtis ${ }^{12}$

(0) 2021 Springer-Verlag GmbH Germany, part of Springer Nature

Correction to: Intensive Care Med (2021) 47:14151425 https://doi.org/10.1007/s00134-021-06544-6 Unfortunately, the name of one of the authors was misspelled. Please find the correct name below:

Sherihane Bensemmane.

Also affiliation $n .10$ and $n .11$ have been updated (see author's details below). The authors apologize for the mistakes.

\section{Author details}

${ }^{1}$ King's College Hospital, London SE5 9RS, UK. ${ }^{2}$ School of Medicine, Human Health Sciences, Kyoto University, Kyoto, Japan. ${ }^{3}$ Bloomsbury Institute of Intensive Care Medicine, University College London, London, UK. ${ }^{4}$ Health Services Research, Epidemiology and Public Health, Sciensano, Brussels, Belgium. ${ }^{5}$ van Dusseldorp, Delvaux en Ket, Groningen, The Netherlands. ${ }^{6}$ Division of Primary Care and Population Health, Department of Medicine, Palliative Care Section, Stanford University, Stanford, CA 94305, USA. ${ }^{7}$ Department of Anesthesiology, Perioperative, and Pain Medicine, Stanford University, Stanford, CA 94305, USA. ${ }^{8}$ Department of Nursing, University of California, San Diego Health Sciences, San Diego, USA. ${ }^{9}$ Centrum voor Intensive Care, Medisch Centrum Leeuwarden, PO Box 888, 8901 BR Leeuwarden, The Netherlands. ${ }^{10}$ Department of Anesthesiology and Intensive Care Medicine, Charité Universitätsmedizin Berlin, Berlin, Germany. ${ }^{11}$ Klinik Bavaria Kreischa, Kreischa, Germany. ${ }^{12}$ Division of Pulmonary, Critical Care and Sleep Medicine, Cambia Palliative Care Center of Excellence at UW Medicine, University of Washington, 325 Ninth Avenue, Box 359762, Seattle, WA 98104, USA.

\section{Publisher's Note}

Springer Nature remains neutral with regard to jurisdictional claims in published maps and institutional affiliations.

Published: 21 December 2021

*Correspondence: victoria.metaxa@nhs.net

1 King's College Hospital, London SE5 9RS, UK

Full author information is available at the end of the article

\section{实

